\title{
Cultural heritage of astronomical observatories
}

\author{
Gudrun Wolfschmidt \\ Institute for History of Science, Hamburg University, \\ Bundesstraße 55 Geomatikum, D-20146 Hamburg, Germany \\ email: wolfschmidt@math.uni-hamburg.de
}

\begin{abstract}
We present the results of the ICOMOS international symposium "Cultural Heritage of Astronomical Observatories (around 1900) - From Classical Astronomy to Modern Astrophysics" (Oct. 2008). The objective of the symposium was to discuss the relevance of modern observatories to the cultural heritage of humankind and to select partner observatories which, due to the date of their construction or to their architectural or scientific importance are comparable to Hamburg Observatory, as international cooperation partners for a serial trans-national application.
\end{abstract}

Keywords. Observatories, astrophysics, history, instruments, architecture, cultural heritage

\section{Introduction}

From October 14 to 17, 2008 an international ICOMOS symposium about "Cultural Heritage of Astronomical Observatories (around 1900) - From Classical Astronomy to Modern Astrophysics" took place, organised and chaired by Gudrun Wolfschmidt with financial support by the Hamburg cultural ministry and other sponsors. The objective of the symposium was to discuss the relevance of modern observatories to the cultural heritage of humankind. Guests from 20 countries discussed cultural heritage of observatories and presented papers which described in detail the history of the buildings and architectural features as well as the valuable instruments of the observatories. But some more research remains to be done to analyse of their architectural relevance and urbanistic significance, as well as an evaluation of their inherent artistic and aesthetic values.

\section{Architecture of observatories}

The first modern observatories after the invention of the telescope were erected in the 17th century in Paris (1667) and Greenwich (1675) (Müller 1992). Around 1800 Gotha was the leading observatory in Europe, built in 1788, where in 1798 the first international astronomical congress was organised by Franz Xaver von Zach (1754-1832). The typical architecture around 1800 was an observatory with one dome on the top of the main building as in Göttingen (1816), where Carl Friedrich Gauß (1777-1855) was acting as director. Other important examples of early one-dome observatories are Tartu Observatory (Estonia), founded in 1802, and Lisbon (Portugal), founded in 1861. The old Hamburg Observatory, initiated by Johann Georg Repsold (1771-1830) and built by the architect Hinrich Anton Christian Koch (1758-1840) in 1825, had two domes, an unusual case, but it was used for both astronomy and navigation (Koch 2001); in 1833 it became a state institution.

Pulkovo Observatory, Saint Petersburg (Russia), was in respect to architecture especially formative for the 19th century with its shape: besides the dominant central dome 

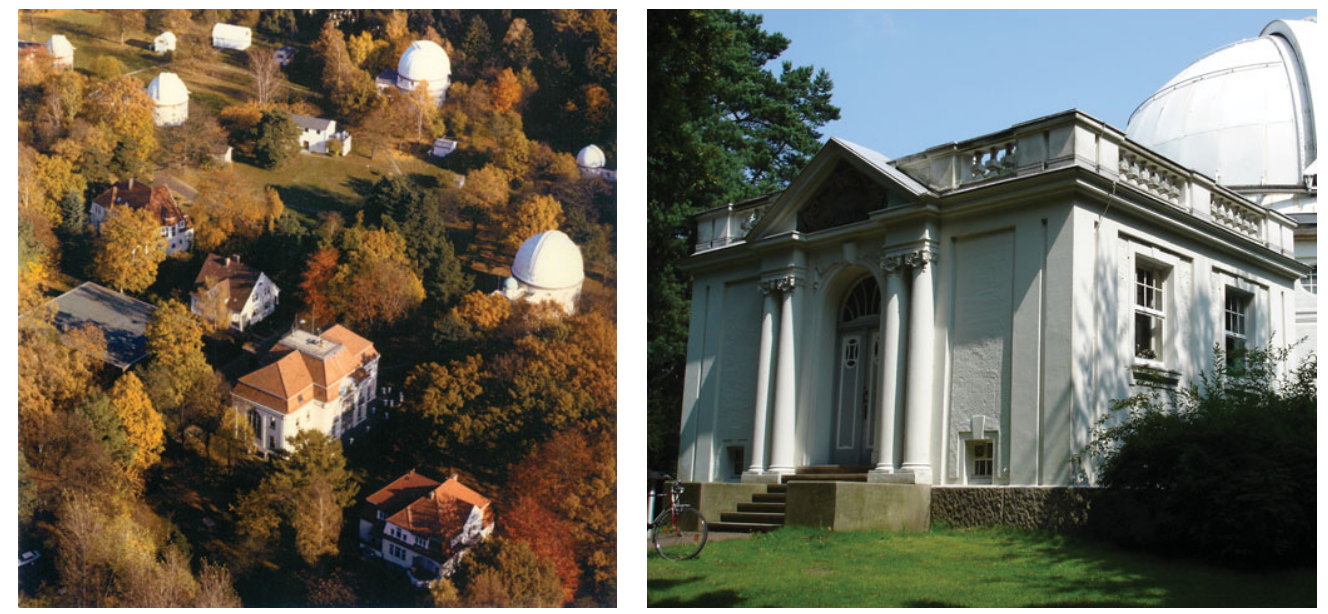

Figure 1. The observatory in Hamburg-Bergedorf, 1906-1912, view of the ensemble in the park, and the large refractor building

there were two smaller domes, for a refractor and a heliometer, and in between there were the slits for the meridian circles. In 1882 there existed 81 observatories (privately and publicly financed) in Europe, including 29 in Germany, 14 in England, 19 in Russia and in addition 28 in America.

A new idea, a revolution in observatory architecture, started in Strasbourg, realised by the architect Hermann Eggert (1844-1920), specialist for prestigious buildings. Three parts are separated: first, the main building with workspaces and the library and with the dome containing the large refractor; second, the two domes with smaller instruments and third, the residential building (Wolfschmidt 2005a,b) $\dagger$. The buildings are connected by sheltered corridors. In addition Strasbourg Observatory shows in an excellent way the integration of the observatory building and other university buildings in urban planning.

The next step was the invention of the observatory park: The "Observatoire de la Côte d'Azur", Nice, was established as a modern park observatory, a group of buildings in a park (Le Guet Tully 2008). In addition another feature can be found here: it is built not in the middle of a city but on a mountain: on the top of Mont Gros near Nice, in 1879-1888. Also the "Observatorio de La Plata", Argentina, is very similar in structure: the main building and all the domes are spread in an astronomy park.

Built on a hill at the border of the city, the new Hamburg Observatory (Fig. 1) fulfills the conditions of modern observatory architecture. It was embellished on a large scale as an ensemble in the astronomy park with a good view of all domes to the south, essential for astronomical observation. Albert Erbe (1868-1922) built this new observatory in Hamburg-Bergedorf in neobaroque style from 1906 to 1912: residential building, main building, director's villa, building of the facility manager, five domes and the meridian circle (Schramm 1996). Richard Schorr (1867-1951), director of the observatory, succeeded in obtaining an impressive instrumentation from the Hamburg State and also from private sponsors. It was one of the most modern observatories in Europe and equipped with the best instruments: classical refractors, equatorials and meridian circles but also modern astrophysical instruments like astrographs and reflecting telescopes with spectrographs and photometers.

$\dagger$ The separation of the domes and the meridian building from the main building was completed in Bamberg Observatory in 1889 and in Marseille in 1879. 


\section{Change of research field: From classical astronomy to modern astrophysics}

\subsection{Navigation, time keeping and astronomy}

In some observatories near the coast, time keeping and the teaching of navigation were important tasks for astronomers. It is clear that this had a special meaning for society and culture. Typical instruments for time keeping are pendulum clocks, chronometers, plugboard of the clock for sending time signals to the time balls for navigation and to the clock at the stock exchange, important for the economy. The best examples are Greenwich Observatory with the first time ball and the U.S. Naval Observatory in Washington, D.C., founded around 1910. In the context of navigation, time keeping and chronometer testing played an important rôle also in the Hamburg Observatory. In 1876, during the directorship of George Rümker (1832-1900), the Hamburg time ball was erected.

\subsection{Positional astronomy with meridian circles}

The important task of classical astronomy was the determination of stellar coordinates. Pulkovo was the leading observatory in that field and served as a model observatory for the 19th century. Typical examples of meridian circles can be found in the observatories of Munich, Strasbourg and Nice. Important examples where this meridian astronomy was done, are Algiers (Algeria, 1856), and Rio de Janeiro (Brasil, 1827). This positional astronomy with meridian circles for the compilation of stellar catalogues also played the dominant rôle in research in the Hamburg Observatory until the 20th century.

\subsection{The rise of astrophysics}

Simon Newcomb (1835-1909) wrote in 1888: "[...] that the age of great discoveries in any branch of science had passed by, yet so far as astronomy is concerned, it must be confessed that we do appear to be fast reaching the limits of our knowledge" (Newcomb 1888). But he was wrong. In the second half of the 19th century a new, a revolutionary branch of astronomy began to be practised -the New Astronomy- in contrast to classical positional astronomy and celestial mechanics. The main point of research had crossed over from classical positional astronomy to the new astrophysics.

Around 1860 astronomy underwent a revolution. Astronomers began to investigate the properties of celestial bodies with physical and chemical methods. New topics in astrophysics came up: photometry, astrophotography, spectroscopy and solar physics. William Huggins (1824-1910) became a pioneer of astrophysics and described the change in his Tulse Hill Observatory near London in 1862, where he observed together with his wife Lady Margaret Lindsay Huggins (1848-1915):

"Then [1862] it was that an astronomical observatory began, for the first time, to take on the appearance of a laboratory: Primary batteries, giving forth noxious gases, ... a large induction coil ... several Leyden jars; shelves with Bunsen burners, vacuum tubes, and bottles of chemicals ... lined its walls. ... In February 1863 the strictly astronomical character of the Observatory was further encroached upon by the erection, in one corner, of a small photographic tent, furnished with baths and other appliances for the wet collodion process ..." Huggins \& Huggins (1899)

In the context of "classical astronomy", only the direction of starlight was studied. In the 1860s quantity and quality of radiation were studied for the first time. This was the beginning of modern "astrophysics", a notion coined in 1865 by the Leipzig astronomer Karl Friedrich Zöllner (1834-1882). Since the 1860s photometers were used for a precise measurement of brightness of the stars; stars with variable brightness are especially important and instructive for astronomers. 
Especially after 1887 (astrophotographical congress with the introduction of the Henry Brothers' standard astrograph) the new technique of photography helped to study and archive faint stars and nebulae. Besides astrographs, portrait lenses and reflectors were used.

Spectroscopy became the most important part of astrophysics and was used especially together with photography†.

Also, solar physics started in the second half of the 19th century. Many solar eclipse expeditions were undertaken since the 1860sł. The Meudon Observatory near Paris (1876) is an early foundation dedicated especially to solar physics. Further interesting examples are Pic du Midi (France, 1878, 1908), Kodaikanal Solar Observatory (India, 1899), and Mt. Wilson Observatory (California, 1904).

\subsection{Centres of astrophysics}

3.4.1. Institutionalisation of astrophysics, 1874-1914-

Potsdam - the first institute of astrophysics in the world

An important enterprise was the foundation of the Astrophysical Observatory in Potsdam, near Berlin, built in 1876-79. It was the first observatory in the world especially dedicated to the new field of astrophysics - a foundation that inspired others (Wolfschmidt 1997). But Pulkovo Observatory still served as a model for the architectural design of the observatory with three domes on the top of the main building and for the choice of instruments (no reflector was ordered). Important innovations and discoveries were made in Potsdam like the first photographic measurement of radial velocities of stars or the discovery of the first spectroscopic binary by Hermann Carl Vogel (1841-1907), first director in 1882, or the discovery of interstellar gas in 1904 by Johannes Hartmann (1865-1936).

\subsubsection{Centres of astrophysics in Germany}

In the last quarter of the 19th century only a few centres of astrophysics existed in the world. Besides Potsdam one should mention in Germany: Göttingen, Heidelberg, Bonn, Bamberg, Hamburg and the Berlin Observatory in Potsdam-Babelsberg. But, around $1900,80 \%$ of the German observatories were still dominated by classical astronomy, which was an important tradition in Germany. It is planned to have a closer look at the development of astrophysics in Germany; a "National Focal Point" was founded in Hamburg. I have sent an application for financial support to Hamburg University to study these German observatories in detail in comparison to Hamburg.

\subsubsection{Centres of astrophysics in Europe}

Soon observatories in England, France, Italy (Rome, Osservatorio del Collegio Romano), Hungary (Konkoly Observatory in O'Gyalla, later in Budapest) and Russia started doing astrophysics, and some famous observatories got astrophysical departments in the 1870s and 1880s: the solar observatory Meudon near Paris (1876), the establishment of an astrophysical department in Greenwich in the 1870s, an astrophysical department in Pulkovo Observatory (1882), and the Solar Physics Observatory in South Kensington, London, in 1885 (besides the already mentioned Huggins Observatory).

$\dagger$ An important breakthrough in that field took place in Potsdam Astrophysical Observatory: Julius Scheiner (1858-1913) succeeded in photographing the spectrum of the Andromeda nebula, and recognised the Andromeda nebula as a stellar system outside of our Milky Way.

$\ddagger$ In Hamburg Observatory for example solar eclipse expeditions were organised to Spain in 1860, Algeria in 1905, Mexico in 1923, Jokkmokk in 1927 and The Philippines in 1929. A horizontal solar telescope was erected by Bernhard Schmidt in 1913. 


\subsubsection{Centres of astrophysics in America}

In the 1890s astrophysics started in the USA: Harvard College Observatory, already founded in 1846, Lick Observatory, Mt. Hamilton (1888), Yerkes Observatory, Wisconsin, University of Chicago (1897) and Mount Wilson (1904).

\section{Change in instrumentation}

\subsection{The importance of reflectors}

The new field of astrophysics caused, and was caused by, new instrumentation: spectrographs, instruments for astrophotography, photometers and solar physics instruments. The new glass-mirror reflecting telescopes are very useful for spectroscopy and photography. Amateur astronomers, especially, recognised the importance of reflectors for astrophysical research. Foucault's silvered glass-mirror reflecting telescope in Marseille is one of the early successful reflectors. In 1911 Hamburg Observatory got a 1-m-reflector, the fourth largest in the world, made by Zeiss of Jena. But the triumph of reflectors took place in the USA in the beginning of 20th century (Mt. Wilson: 60 inches $=1.5 \mathrm{~m}$ reflector and the Hooker telescope, 100 inches $=2.5 \mathrm{~m}$ ).

\subsection{Invention of the Schmidt telescope - Hamburg as a Model Observatory}

Finally the Schmidt telescope was the most important and influential invention in the Hamburg Observatory, made by Bernhard Schmidt (1879-1935) in 1930; now one can find Schmidt telescopes all over the world. Hamburg served as a model for the Merida Observatory (first in Caracas, Venezuela), with the whole instrumentation; besides a large refractor, astrographs, meridian circle and a reflecting telescope, there exists also a large Schmidt telescope.

\section{Conclusion}

The change from classical astronomy to modern astrophysics can be seen very well in several observatories around 1900 -especially in Hamburg- concerning the choice of instruments, the architecture and the idea of the astronomy park; all this is an important cultural heritage connected with observatories of that time. The urbanistic complex, the buildings and their architecture, the quality of instruments, the scientific archives (collections of photographic plates, observation books, correspondence, star catalogues, etc) as well as the scientific/intellectual achievements, inventions and discoveries made by the persons related to the individual observatory are all to be understood as categories of the cultural heritage (also in terms of scientific heritage). This corresponds to the main categories according to which the "outstanding universal value" (UNESCO criteria ii, iv and vi) of the observatories will have to be evaluated: historic, scientific, and aesthetic. The goal of the ICOMOS symposium was to select partner observatories, which due to the time of their erection or to their architectural, scientific or instrumental heritage are comparable to Hamburg Observatory, as international cooperation partners for a serial trans-national application for inscription in the UNESCO World Heritage List†. These twelve observatories were chosen in discussion with the Conservation Department

$\dagger$ Such a trans-national serial application corresponds to the "global strategy for a credible, representative and balanced World Heritage List" as pursued since 1994 by the World Heritage Centre (WHC) and the World Heritage Committee of UNESCO in order to fill existing regional, geographical and thematic gaps, as defined in 2004 by ICOMOS International with its action plan "Filling the Gaps". 
of Hamburg and with Prof. Dr. Michael Petzet, former president of ICOMOS. This first proposal is based on the criteria of a comparability of $t$ he twelve introduced observatories in terms of the urbanistic complex and the architecture, the scientific orientation, equipment of instruments, authenticity and integrity of the preserved state, as well as in terms of historic scientific relations and the historic relevance of the persons who worked at the observatories. A significant fact was also that among these observatories there were some which are parts of an already existing World Heritage site, but which would nevertheless be of advantage in the separate nomination process for a series of observatories as World Heritage. The following observatories were recommended:

- Algeria: Observatoire d'Alger

- Argentina: Observatorio de La Plata (proposed to lead this application)

- Brasil: Observatory Rio de Janeiro (Museu de Astronomia e Ciências afins)

- England: Royal Observatory Greenwich (WH 795 "Maritime Greenwich")

- Estonia: Tartu, Old Observatory (WH 1187 "Struve Geodetic Arc")

- France: Observatoire de Paris-Meudon

- France: Observatoire de la Côte d'Azur, Nice

- Germany: Observatory in Hamburg-Bergedorf

- India: Kodaikanal Observatory of the Indian Institute of Astrophysics

- Portugal: Observatório Astronómico de Lisboa

- Russia: Nikolas Central Astronomical Observatory Pulkovo, St. Petersburg (WH 540 "Historic Centre of Saint Petersburg and Related Groups of Monuments")

- USA: US Naval Observatory (USNO), Washington D.C.

These observatories contributed remarkably to astronomical science, to our modern view of the world. An extension of this study in two directions is planned, first the early observatories from Renaissance and Baroque time should be studied in more detail, second the contemporary astronomy (radio astronomy, new wavelength astronomy and new technology telescopes) should be discussed.

\section{References}

Huggins, W. \& Huggins, M. 1899, An Atlas of Representative Stellar Spectra. Vol. I (London: Publications of Sir William Huggins's Observatory)

Koch, J. W. 2001, Der Hamburger Spritzenmeister und Mechaniker Johann Georg Repsold (1770-1830), ein Beispiel für die Feinmechanik im norddeutschen Raum zu Beginn des 19. Jahrhunderts. (Norderstedt: BoD)

Le Guet Tully, F. 2008, in Astronomisches Mäzenatentum, G. Wolfschmidt (ed) Nuncius Hamburgensis; Band 11 (Norderstedt: BoD), p. 111

Müller, P, 1992, Sternwarten in Bildern. Architektur und Geschichte der Sternwarten von den Anfängen bis ca. 1950. (Berlin and Heidelberg: Springer)

Newcomb, S. (1888), Sideral Messenger, 7, 14 and 65

Schramm, J. 1996, Sterne über Hamburg. (Hamburg: Kultur- und Geschichtskontor)

Wolfschmidt, G. 1997, Genese der Astrophysik, Habilitation (München: Ludwig-MaximiliansUniversität München)

Wolfschmidt, G. 2005a, in The Multinational History of Strasbourg Astronomical Observatory, A. Heck (ed) Astrophysics and Space Science Library, Vol. 330 (Dordrecht: Springer), p. 63

Wolfschmidt, G. 2005b, in La Science sous influence. L'Université de Strasbourg enjeu des conflits franco-allemands 1872-1945, E. Crawford \& J. Olff-Nathan (eds) (Strasbourg: Université Louis Pasteur et La Nuée Bleue), p. 91 and p. 215 